\title{
Impact of Knowledge and Attitude on Saudis' Physical Activity Practice and Inactivity Barriers: A Questionnaire-based Study
}

\author{
Naif N. Albalawi ${ }^{1}$, Moath M. Alshehri ${ }^{1}$, Moshari A. Al-Ghamdi ${ }^{1}$, Mohammed A. Alshehri ${ }^{1}$, Mohamed S. Abdel-Maksoud ${ }^{2}$, \\ Mohammed M. H. Al-Gayyar ${ }^{3,4,5 *}$ \\ ${ }^{1}$ PharmD Program, Faculty of Pharmacy, University of Tabuk, Tabuk, Saudi Arabia; ${ }^{2}$ Department of Pharmacology and \\ Toxicology, Faculty of Pharmacy, University of Tabuk, Tabuk, Saudi Arabia; ${ }^{3}$ Department of Biochemistry, Faculty of Pharmacy, \\ Mansoura University, Mansoura, Egypt; ${ }^{4}$ Department of Pharmaceutical Chemistry, Faculty of Pharmacy, University of Tabuk, \\ Tabuk, Saudi Arabia; ${ }^{5}$ PharmD Program Coordinator, Faculty of Pharmacy, University of Tabuk, Tabuk, Saudi Arabia
}

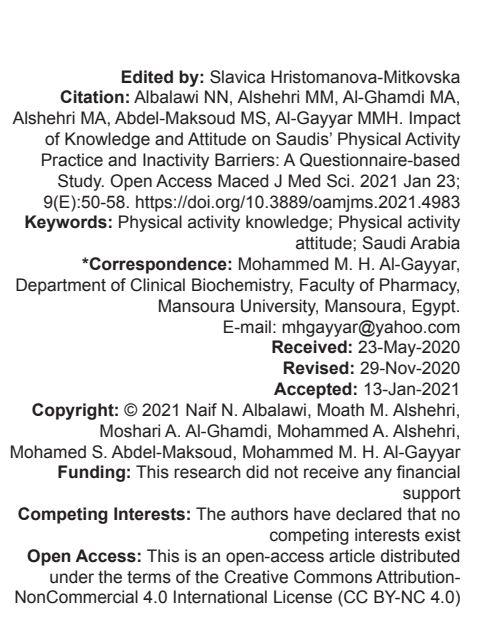

\section{Abstract}

BACKGROUND: Community participation in physical activity is considered a major public health preference of WHO. Saudi Arabia in the last decades faced many tremendous economic changes leading to adoption of western dietary habits associated with sedentary lifestyle.

AIM: We aimed to study the relationship between both physical activity knowledge and attitude of community to the practice of individuals.

METHODS: We used a questionnaire consists of a mixture of closed-ended questions. Participants were recruited through direct meetings in local markets, schools, and workplaces. Seven hundred and sixty six individuals agreed to participate.

RESULTS: Overall correct answers to questions about importance of physical activity were $76.58 \%$. The predominance of participants' attitude was to establish public places for physical activity in each neighborhood (92.1\%). Participants acknowledged that they exercise to improve their health (47.5\%). Participants mainly perform light exercises $(47.2 \%)$ on basis of $1-3$ times weekly $(48.9 \%)$. About $90.8 \%$ of participants admitted that they like to increase duration of their physical activity.

CONCLUSIONS: Overall physical activity practice of participants' needs encourage overcoming obstacles that prevent individuals from practicing especially lack of time.

\section{Introduction}

Physical activity is defined as any body movement that is produced by skeletal muscles and associated with energy expenditure [1]. It helps in maintaining physical fitness by enhancing muscles movement, as well as mental health fitness by boosting individuals' mode. Physical activity includes playing games, exercise, dance, gardening, walking, or cycling [2]. Motivation and support are highly needed to help people to participate in physical activity [3]. In the last decades, Saudi Arabia faced tremendous economic changes leading to adoption of western dietary habits associated with sedentary lifestyle. All these changes resulted in negative influence on community health and enhance the spread of non-communicable diseases [4].

Physical activity is a powerful public health measure for decreasing many non-communicable chronic diseases such as obesity, diabetes, cardiovascular diseases, metabolic disorders, and cancer risk. In addition, physical inactivity contributes to risk of developing a number of cancers through its relation to energy balance [1]. Physical inactivity is considered the principal factor in about $30 \%$ of ischemic heart disease, $27 \%$ of diabetes, and $21-25 \%$ of breast and colon cancer [5]. There is a synergistic relationship between overweight or obesity and the physical inactivity in association with the spectrum of cancer prevention and survivorship [6]. Physical activity is also a useful adjunct to improve side effects experienced during cancer treatment. These side effects may include fatigue, muscular weakness, deteriorated functional capacity of, and many others [7]. Exercise has a number of biological effects on the body, including reducing inflammation, improving immune system function, helping to prevent obesity, and decreasing the harmful effects of obesity [1].

It has been reported that about $30 \%$ of worldwide adults lack sufficient levels of physical activity [8]. Inactivity and idleness have increased recently due to modern life style, which is characterized by lack of enough time and presence of other motivation that enhance laziness life. Lack of physical activity 
is responsible of about two million deaths (6-10\%) caused by coronary heart disease, cancer, and diabetes especially and about $2.1 \%$ of disability-adjusted life in the low- and middle-income countries [9].

Many factors were reported previously to be barriers of physical activity. They are classified into time, motivation and support, facilities, and personal factor [10]. Many efforts are needed to reduce physical activity barriers such as increasing availability and improving of physical activity-related equipment and facilities [11]. Therefore, we conducted this study to assess the knowledge and attitude of the community and their effect on physical activity practice in Saudi Arabia. Within this context, we want to verify the association of physical activity, sociodemographic characteristics, and health conditions with disease knowledge and attitudes in Saudi population. This helps to direct health recommendation to policy makers for improvement and promote health life in society. In clinical prospect, new health plans will enhance the quality of life and help in reducing the risk of cardiovascular diseases.

\section{Materials and Methods}

\section{Study design and settings}

This study was a part of a large cross-sectional questionnaire-based study in Saudi Arabia about the effect of life style behavior on participants. It was conducted in the period between December 2018 and June 2019. It depends on both personal face-to-face and online methods.

\section{Study population}

The direct face-to-face part was conducted inside the University of Tabuk as well as the local schools, markets and workplaces. The inclusion criteria consists of being 18 years or older, ability to participate in the interview and acceptance to complete the written consent. Socioeconomic characteristics of participants were summarized in Table 1.

\section{Ethical consideration and informed consent}

The study protocol was approved by the Local Ethical Committee in University of Tabuk, under number UT-70-22-2018. During the meeting with participants, we discussed the aims of the study. All participants' information was kept confidential and their responses were coded. All participants were aware that they have the full right to refuse participation or quit the study at any time without any type of risk. Written consent
Table 1: Socioeconomic characteristics of participants

\begin{tabular}{|c|c|c|}
\hline Characteristics & Number & Percent \\
\hline \multicolumn{3}{|l|}{ Gender } \\
\hline Male & 572 & 74.7 \\
\hline Female & 175 & 22.8 \\
\hline Do not want to determine & 19 & 2.5 \\
\hline \multicolumn{3}{|l|}{ Age } \\
\hline$<30$ years & 261 & 34.1 \\
\hline $30-39$ years & 210 & 27.5 \\
\hline $40-49$ years & 214 & 27.9 \\
\hline $50-59$ years & 73 & 9.5 \\
\hline $60-65$ years & 7 & 0.9 \\
\hline More than 65 years & 1 & 0.1 \\
\hline \multicolumn{3}{|l|}{ Job } \\
\hline Employee & 446 & 58.2 \\
\hline Employer & 34 & 4.4 \\
\hline Unemployed & 116 & 15.2 \\
\hline Retired & 75 & 9.8 \\
\hline Did not determine & 95 & 12.4 \\
\hline \multicolumn{3}{|l|}{ Income } \\
\hline$<5000$ SAR & 222 & 28.9 \\
\hline $5000-10,000$ SAR & 146 & 19.1 \\
\hline $10,000-20,000$ SAR & 280 & 36.6 \\
\hline More than 20,000 SAR & 106 & 13.8 \\
\hline Did not determine & 12 & 1.6 \\
\hline \multicolumn{3}{|l|}{ Accommodation } \\
\hline Urban & 649 & 84.7 \\
\hline Rural & 115 & 15.0 \\
\hline Did not determine & 2 & 0.3 \\
\hline \multicolumn{3}{|l|}{ Education } \\
\hline Post-graduation degrees & 137 & 17.9 \\
\hline University degree & 403 & 52.6 \\
\hline High and intermediate school certificates & 226 & 29.5 \\
\hline \multicolumn{3}{|l|}{ Marital status } \\
\hline Married & 538 & 70.2 \\
\hline Divorced/widowed & 18 & 2.3 \\
\hline Never married & 208 & 27.2 \\
\hline Did not determine & 2 & 0.3 \\
\hline \multicolumn{3}{|l|}{ Family history } \\
\hline No tumor history & 635 & 82.9 \\
\hline $1-2$ family members with tumors & 123 & 16.1 \\
\hline More than 3 family members with tumors & 8 & 1.0 \\
\hline
\end{tabular}

was added in the first page of the survey and on the beginning of the electronic one.

\section{Questionnaire development and design}

The questionnaire was designed according to the aims of the study and compared with previous published work. Before distribution to participants, the research team revised it for clarity, format, and cultural suitability. In addition, the survey was investigated by ten participants to insure the clarity of its questions, easiness of use, and appropriateness of allocated time. The questionnaire consists of closed ended questions. It was written in both Arabic and English languages (Supplementary). It is divided into four parts. The first part is the sociodemographic characteristics as age, gender, profession, income, accommodation, education, marital status, and anthropometric parameters. The second part assesses the physical activity knowledge of participants. The third part evaluated the participants' attitude regarding physical activity. The fourth part estimated the participants' physical activity practice.

\section{Data collection}

Participants, who could participate in the faceto-face questionnaire, were asked to participate on the online version. At the beginning of the questionnaire, participants were asked to sign the consent form. Participants were met privately to explain the aims of 
the study. The responses collected from participants were coded and processed confidentially.

\section{Statistical analysis}

The results were expressed as percent value and mean \pm standard error. Statistical computations were performed by SPSS program version 25 .

\section{Results}

After inviting more than one thousand individuals, only 860 agreed to participate. However, only 766 individuals completed the whole questionnaire.

\section{Physical activity knowledge of participants}

Overall correct answers to questions about health importance of physical activity were $79.5 \%$. In addition, the correct answers of questions about psychological effects of physical activity were $73.7 \%$.

\section{Physical activity attitude of participants}

There are four major barriers of physical activity; time, motivation and support, facilities, and personal factors [10]. The participants' choice concentrates on overcoming the major four barriers. The predominance of participants' attitudes was to establish a place for physical activity in each neighborhood $(92.1 \%)$ to overcome the barrier of facilities. Second, they suggest including at least 30 min daily exercise $(81 \%)$ to overcome the personal factors. Third, participants suggest to make physical activity obligatory in workplaces $(75.2 \%)$ to overcome the barrier of time. Finally, they vote to keep constant level of exercise through life $(60.7 \%)$ to overcome the barrier of motivation and support. The least suggestions were limiting sedentary habits as sitting long hours at the computer or television (48\%) and decreasing waistline circumference as one grows older (38.3\%) (Figure 1).

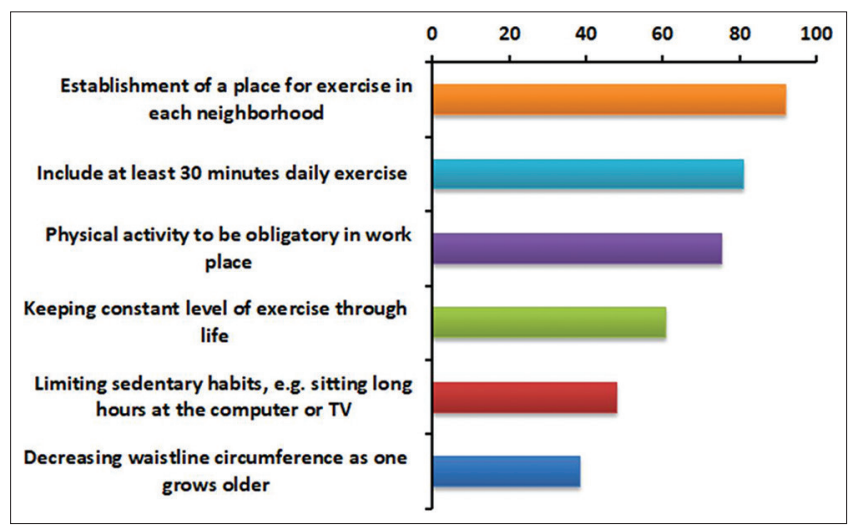

Figure 1: Physical activity attitude of participants

\section{Physical activity practice of participants}

Participants acknowledged that they exercise to improve their health $(47.5 \%)$. Participants mainly perform light exercises $(47.2 \%)$ on basis of $1-3$ times weekly (48.9\%). About $90.8 \%$ of participants admitted that they like to increase duration of their physical activity. However, only $21 \%$ were considered perform physically active with about 30 min more than 3 times weekly. On the other hand, $44.6 \%$ of participants admitted that they did not have enough time to perform regular exercises (Figure 2).

\section{practice \\ Effect of gender on physical activity}

As shown in Figure 3, the gender did not affect the physical activity in the study group. The results are the same in both genders.

\section{Effect of education level on physical activity practice}

About $41.5 \%$ of participants with intermediate and high school education were inactive. This considered high as compared with those with college degree or postgraduate studies with inactive individuals $24.8 \%$ and $28.5 \%$, respectively. According to the reason of practicing, most admitted they practiced to improve their health with different percent according to education, $53.4 \%$ in those with postgraduate studies, 49.9 for college studies, and $37.2 \%$ in those with intermediate or high school education. All other practice was almost the same in participants without any effect of education level (Figure 4).

\section{Effect of income on physical activity practice}

According to Figure 5, all participants practice was not affected by income level except for the need of more exercise. About $96 \%$ of participants with the highest income admitted that they need more practice. Regarding the reasons for inactivity, participants with high income admitted that they did not have enough time $(57 \%)$.

\section{Discussion}

Regular physical activity among all ages produces both physical and mental benefits including improvement of life quality, sleep and stress management, and enhancement of social relationships [12]. Physical inactivity is one of the most important risk factors for developing chronic diseases and increasing morbidity 


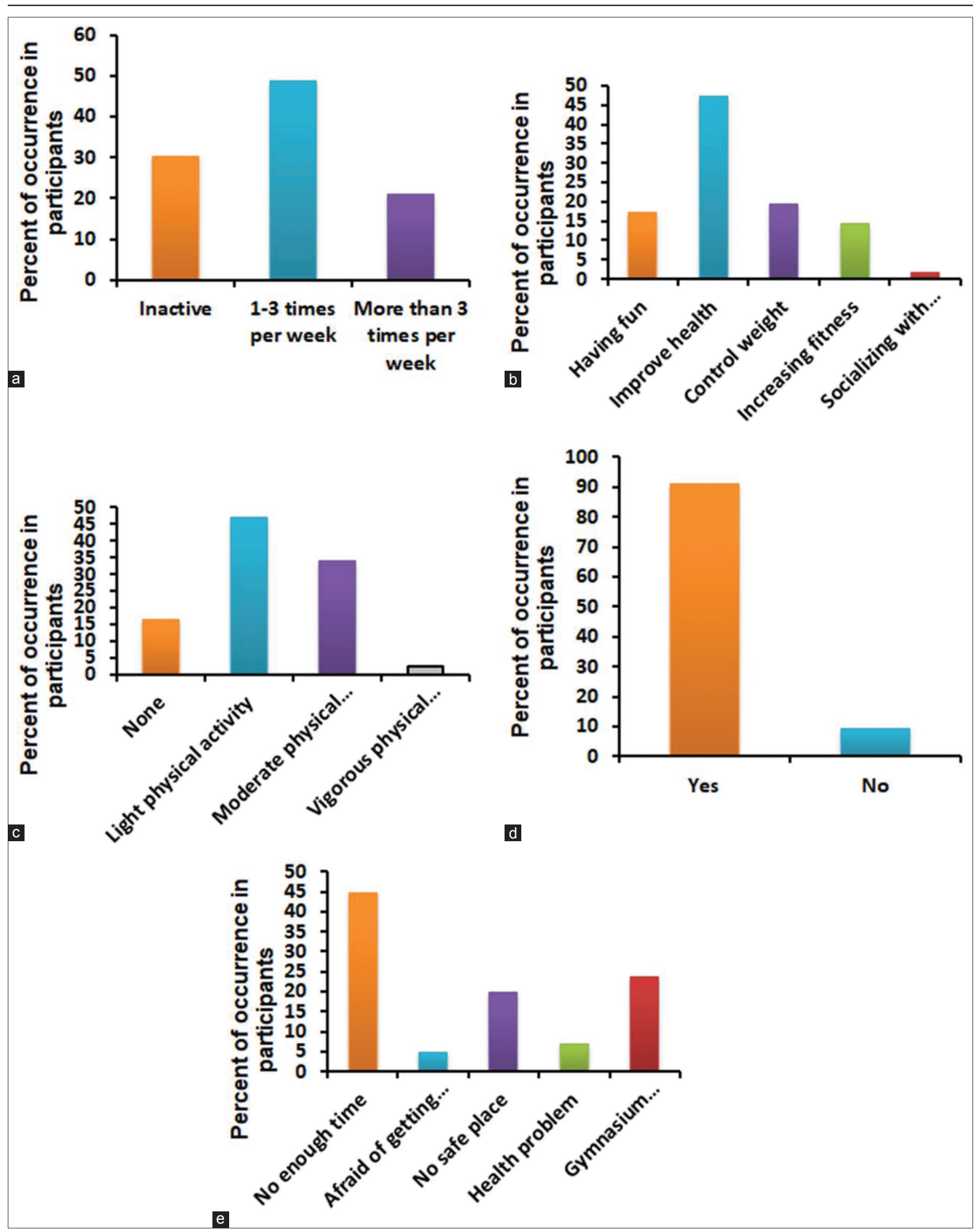

Figure 2: Physical activity practice of participants regarding physical activity level (a), reasons for exercise (b), types of physical activity (c), need for increasing the level of exercise (d), and reasons for not practicing (e)

and mortality [13]. In particular, physical inactivity has major effects on the incidence of coronary heart disease, type 2 diabetes and cancer, specifically breast and colon cancers [9]. According to WHO Country profile $2016,52.1 \%$ of Saudi males and $67.7 \%$ of females did not fulfill the international recommendation of physical 


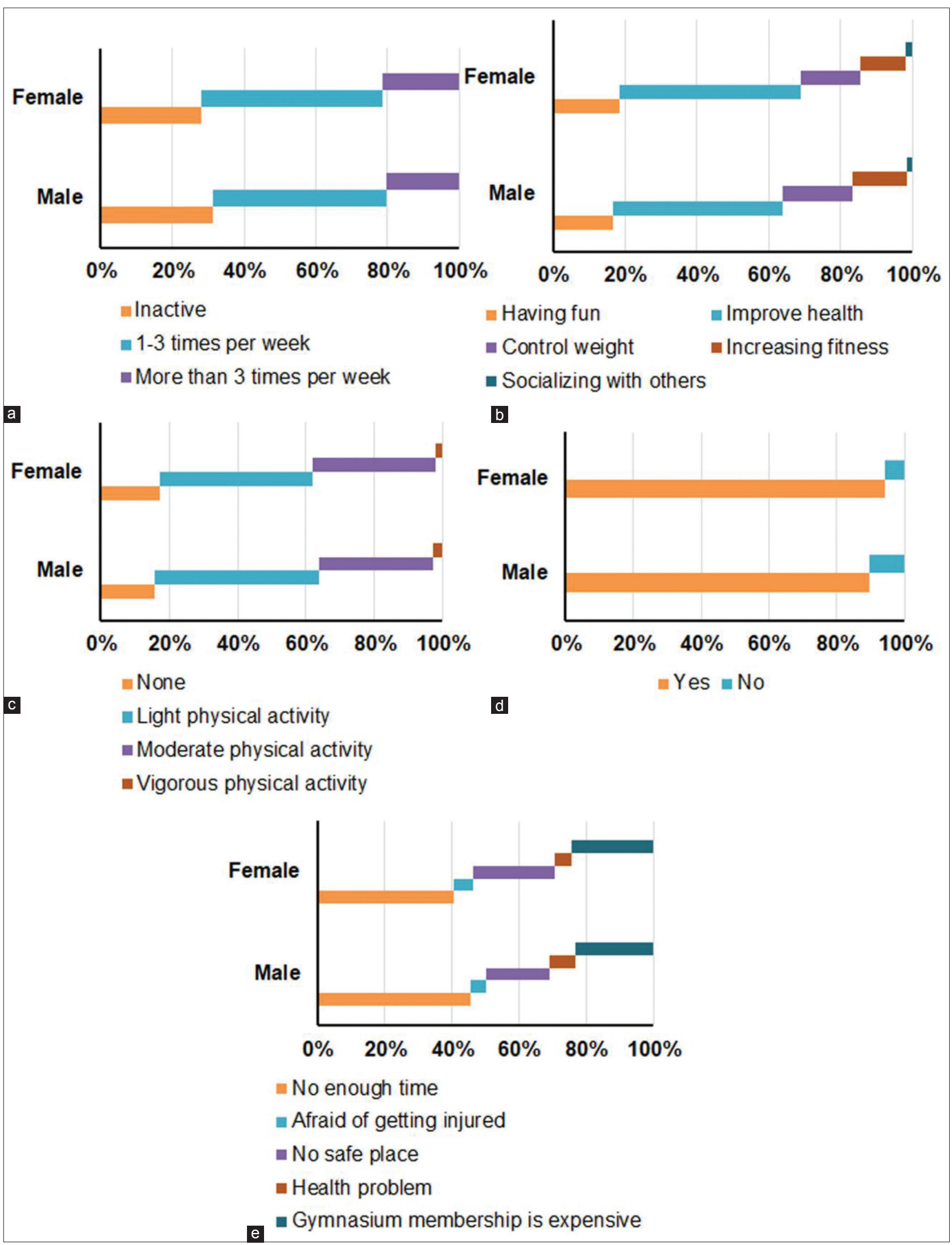

Figure 3: Effect of gender on physical activity practice of participants regarding physical activity level (a), reasons for exercise (b), types of physical activity (c), need for increasing the level of exercise (d), and reasons for not practicing (e)

activity levels. This illustrated a big public health issue [14]. Therefore, this study was designed to explore the relationship between physical activity knowledge, behavior, and practice with cancer. In part, this study helped people to improve their practice by alarming them about the dangerous effects of their behavior. 


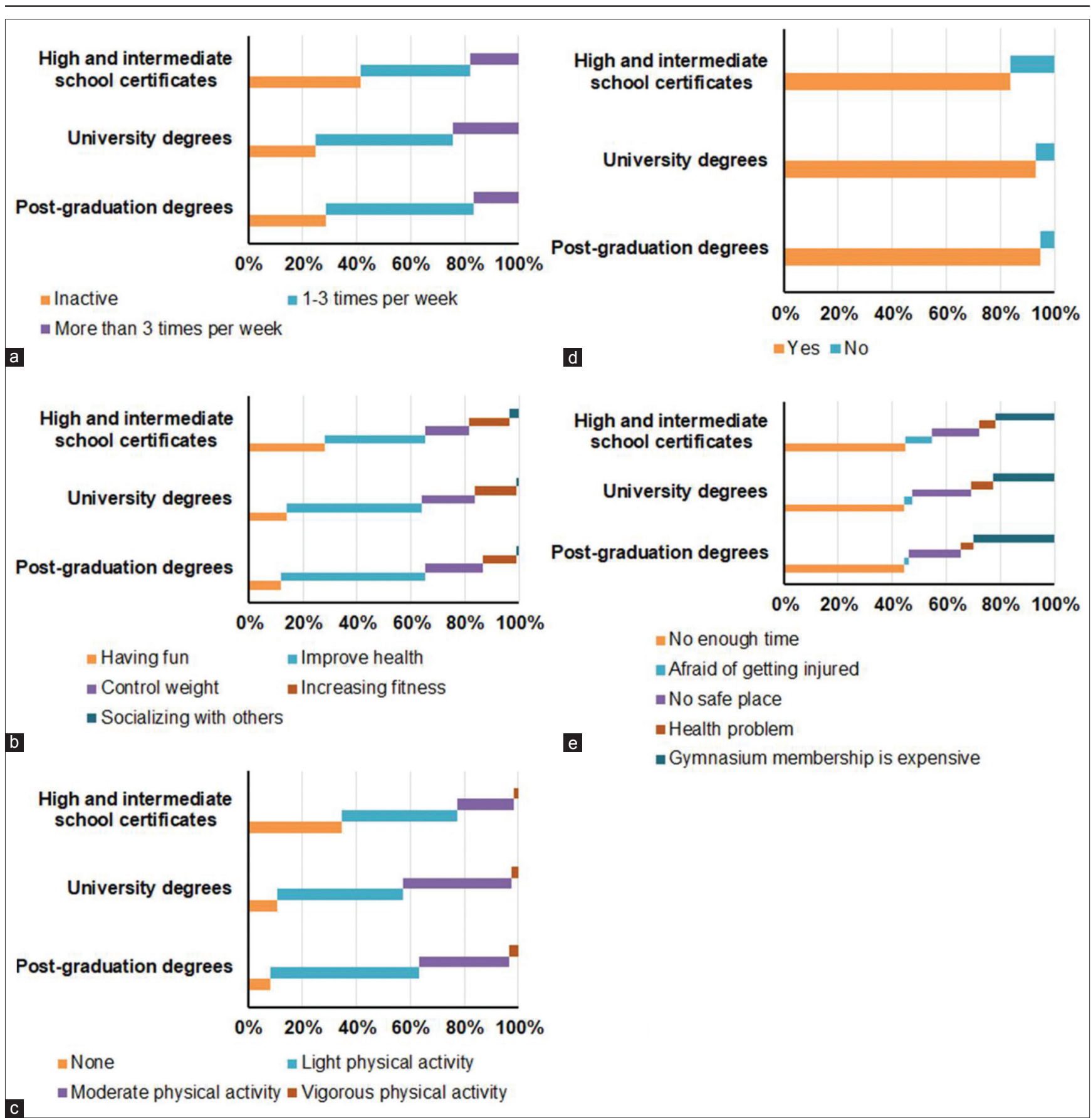

Figure 4: Effect of education level on physical activity practice of participants regarding physical activity level (a), reasons for exercise (b), types of physical activity (c), need for increasing the level of exercise (d), and reasons for not practicing (e)

Participants have good knowledge about both the health and social effects of physical activity. Most of them linked the health effects of physical activity with protection from cancer. However, there is a strong relationship between the lack of physical activity and cancer. There is substantial evidence that higher levels of physical activity are linked to lower risks of several cancers [15]. Colon cancer is one of the most extensively studied cancers in relation to physical activity. A 2009 meta-analysis of 52 epidemiologic studies that examined the association between physical activity and colon cancer risk found that the most physically active individuals had a $24 \%$ lower risk of colon cancer than those who were the least physically active [16]. American guidelines recommend that cancer survivors engage in 150 min per week or more of moderate physical activity [17]. This protection can take place through multiple mechanisms such as reducing adiposity, improving insulin resistance, enhancing immunity, and attenuation of inflammation [18].

We examined the attitude of participants against the external barriers. Most of the external barriers are developed in the participants in their early life. Participants usually focus on the academic life instead of physical activity under encouragement of their parents and teachers planning for future financial 


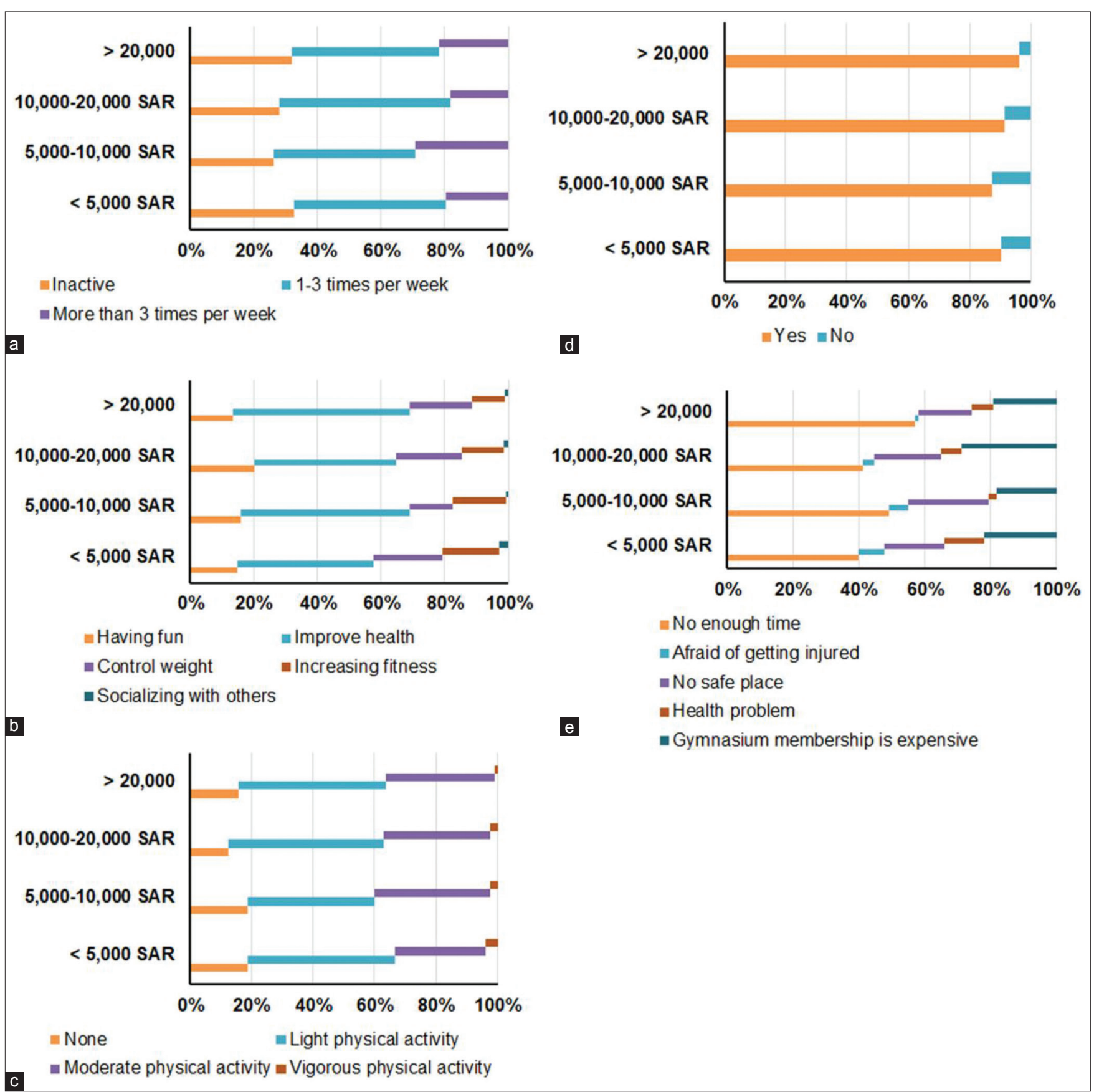

Figure 5: Effect of income on physical activity practice of participants regarding physical activity level (a), reasons for exercise (b), types of physical activity (c), need for increasing the level of exercise (d), and reasons for not practicing (e)

stability. Later, in their life, they develop the concept physical activity is less important than their career achievement. Therefore, self-efficacy is important in adopting physical activity behaviour [19]. In addition, cognitive control has greeter influence in adopting physical activity in life [20]. All these negative concepts were promoted into internal barriers later in their lives and many shares similar socio-cultural beliefs. Participants' suggestion for overcoming these barriers gave the highest percent of vote to elimination of barrier of facilities by suggesting establishment of a place for physical activity in each neighbourhood. Next, they vote for elimination of internal personal barriers by suggesting inclusion of at least 30 min daily exercise.
The third position was to overcome the barrier of time by making physical activity obligatory in workplaces. Finally, participants vote to eliminate the barrier of internal motivation and support by supporting constant levels of physical activity throughout life.

We found that $30 \%$ of the participants are physically inactive. However, only $21 \%$ of participants were considered physically active with $30 \mathrm{~min}$ more than 3 times weekly. Our results are consistent with a previous study in Saudi Arabia [21]. In addition, 30\% of participants admitted that they are physically inactive. It is previously estimated that about $20 \%$ of world's population are physically inactive [22]. A high percent of 
participants did not practice because they did not find enough time. Therefore, we compared our study with other cross-sectional survey among Riyadh city, which illustrated the main reason for not engaging in physical activity was lack of time (58.1\%) followed by work duties $(22.5 \%)$ [23]. Although, our result show considerable amount of knowledge of participants in physical activity and we found more than $80 \%$ of them know both health and social effects physical activity. However, only few of them practice in regular basis blaming the lack of enough time.

Gender is an important factor in determining the physical activity level. It has been reported previously by some studies in Saudi Arabia that women are less active than men [4], [24]. However, in the present study, we found that the physical activity practice is the same in both genders without any variation, which can be attributed to social changes in the community and the increased role of Saudi government to enhance women physical activity in schools and special designed areas. However, the differences in body composition between male and female regarding the highest amount of muscle mass in male as well as the cardiac size and mechanical efficiency is better in males [25].

We found that participants with high education levels were more physically active. These results are consistent with previous studies [26], [27]. However, persons with highest education levels were engaged in jobs with longer sitting times but on other hand, the increased levels of physical activity are mainly associated with enhancing satisfaction of body image. In parallel, we did not find any relationship between physical activity and income level except for feeling for the need of more physical activity with blame on no enough time in participants with the highest income level. Many studies around the world found that individuals with high income featured higher physical activity in US [27] and Korea [28]. However, some studies conclude that there was relationship between physical activity and income [29].

\section{Conclusion}

Participants have good knowledge about importance of physical activity in daily life. Moreover, attitudes of participants were directed towards increasing public places for physical activity and to make it obligatory. Finally, overall physical activity practice of participants' needs encourage to overcome obstacles that prevent individuals from practicing especially lack of time. Therefore, we can conclude that participants had good knowledge and attitude about the physical activity easing the implementation of new plans to promote the health of population.

\section{Ethical Approval}

The work is approved the Local Research Ethics Committee in University of Tabuk (UT-70-22-2018).

\section{Authors' Contributions}

MAA helped in the idea, collected data, and helped in manuscript writing. MMA collected data, helped in design of the work and drafting of the manuscript. NNA collected data, helped in statistics and drafting of manuscript. MAA collected data and helped in the manuscript writing. MSA helped in the idea and performed the statistics. MMHA suggested the idea, wrote the manuscript, and supervised all the work. All authors have approved the final manuscript.

\section{References}

1. Krouse RS, Wendel CS, Garcia DO, Grant M, Temple LK, Going SB, et al. Physical activity, bowel function, and quality of life among rectal cancer survivors. Qual Life Res. 2017;26(11):313142. https://doi.org/10.1007/s11136-017-1641-2

PMid:28677077

2. Rahman MM, Liang CY, Gu D, Ding Y, Akter M. Understanding levels and motivation of physical activity for health promotion among chinese middle-aged and older adults: A cross-sectional investigation. J Healthc Eng. 2019;2019:9828241. https://doi. org/10.1155/2019/9828241

3. Kilpatrick M, Hebert E, Bartholomew J. College students motivation for physical activity: Differentiating men's and women's motives for sport participation and exercise. J Am Coll Health. 2005;54(2):87-94. https://doi.org/10.3200/ jach.54.2.87-94

PMid:16255320

4. Amin TT, Al Khoudair AS, Al Harbi MA, Al Ali AR. Leisure time physical activity in Saudi Arabia: Prevalence, pattern and determining factors. Asian Pac J Cancer Prev. 2012;13(1):35160. https://doi.org/10.7314/apjcp.2012.13.1.351 PMid:22502700

5. Chandrashekar Nooyi S, Murthy SN, Sivananjiah S, Sreekantaiah P, Rajaram D, Gowda V, et al. Metabolic equivalent and its associated factors in a rural community of Karnataka, India. Cureus. 2019;11(6):e4974. https://doi.org/10.7759/ cureus. 4974

PMid:31467809

6. Hursting SD, Berger NA. Energy balance, host-related factors, and cancer progression. J Clin Oncol. 2010;28(26):4058-65. https://doi.org/10.1200/jco.2010.27.9935 PMid:20697088

7. Brown JC, Winters-Stone K, LeeA, Schmitz KH. Cancer, physical activity, and exercise. Compr Physiol. 2012;2(4):2775-809.

PMid:23720265

8. Hallal PC, Andersen LB, Bull FC, Guthold R, Haskell W, 
Ekelund $U$, et al. Global physical activity levels: Surveillance progress, pitfalls, and prospects. Lancet. 2012;380(9838):24757. https://doi.org/10.1016/s0140-6736(12)60646-1

\section{PMid:22818937}

9. Lee IM, Shiroma EJ, Lobelo F, Puska P, Blair SN, Katzmarzyk PT, et al. Effect of physical inactivity on major non-communicable diseases worldwide: An analysis of burden of disease and life expectancy. Lancet. 2012;380(9838):219-29. https://doi. org/10.1016/s0140-6736(12)61031-9 PMid:22818936

10. Samara A, Nistrup A, Al-Rammah TY, Aro AR. Lack of facilities rather than sociocultural factors as the primary barrier to physical activity among female Saudi university students. Int J Womens Health. 2015;7:279-86. https://doi.org/10.2147/ijwh.s80680 PMid:25834468

11. Ranasinghe $C$, Sigera $C$, Ranasinghe $P$, Jayawardena $R$, Ranasinghe AC, Hills AP, et al. Physical inactivity among physiotherapy undergraduates: Exploring the knowledgepractice gap. BMC Sports Sci Med Rehabil. 2016;8:39. https:// doi.org/10.1186/s13102-016-0063-8 PMid:27980791

12. Das $P$, Horton R. Rethinking our approach to physical activity. Lancet. 2012;380(9838):189-90. https://doi.org/10.1016/ s0140-6736(12)61024-1 PMid:22818931

13. Al-Hazzaa HM, Abahussain NA, Al-Sobayel HI, Qahwaji DM, Musaiger AO. Physical activity, sedentary behaviors and dietary habits among Saudi adolescents relative to age, gender and region. Int J Behav Nutr Phys Act. 2011;8:140. https://doi. org/10.1186/1479-5868-8-140

\section{PMid:22188825}

14. Alahmed Z, Lobelo F. Correlates of physical activity counseling provided by physicians: A cross-sectional study in Eastern Province, Saudi Arabia. PLoS One. 2019;14(7):e0220396. https://doi.org/10.1371/journal.pone.0220396 PMid:31344113

15. Van Blarigan EL, Chan H, Van Loon K, Kenfield SA, Chan JM, Mitchell E, et al. Self-monitoring and reminder text messages to increase physical activity in colorectal cancer survivors (Smart Pace): A pilot randomized controlled trial. BMC Cancer. 2019;19(1):218. https://doi.org/10.1186/s12885-019-5427-5 PMid:30866859

16. Wolin KY, Yan Y, Colditz GA, Lee IM. Physical activity and colon cancer prevention: A meta-analysis. $\mathrm{Br} \mathrm{J}$ Cancer. 2009;100(4):611-6. https://doi.org/10.1038/sj.bjc.6604917 PMid:19209175

17. Rock CL, Doyle C, Demark-Wahnefried W, Meyerhardt J, Courneya KS, Schwartz AL, et al. Nutrition and physical activity guidelines for cancer survivors. CA Cancer J Clin. 2012;62(4):243-74. https://doi.org/10.3322/caac.21142 PMid:22539238

18. Kruk J, Czerniak U. Physical activity and its relation to cancer risk: Updating the evidence. Asian Pac J Cancer Prev. 2013;14(7):39934003. https://doi.org/10.7314/apjcp.2013.14.7.3993 PMid:23991944

19. McAuley E, Blissmer B. Self-efficacy determinants and consequences of physical activity. Exerc Sport Sci Rev. 2000;28(2):85-8.

PMid:10902091

20. McAuley E, Jerome GJ, Marquez DX, Elavsky S, Blissmer B. Exercise self-efficacy in older adults: Social, affective, and behavioral influences. Ann Behav Med. 2003;25(1):1-7. https:// doi.org/10.1207/s15324796abm2501_01

PMid: 12581930

21. Amin TT, Al-Hammam AM, AIMulhim NA, Al-Hayan MI, Al-Mulhim MM, Al-Mosabeh MJ, et al. Physical activity and cancer prevention: Awareness and meeting the recommendations among adult Saudis. Asian Pac J Cancer Prev. 2014;15(6):2597606. https://doi.org/10.7314/apjcp.2014.15.6.2597

PMid:24761870

22. Dumith SC, Hallal PC, Reis RS, Kohl HW. Worldwide prevalence of physical inactivity and its association with human development index in 76 countries. Prev Med. 2011;53(1-2):248. https://doi.org/10.1016/j.ypmed.2011.02.017 PMid:21371494

23. Mandil AM, Alfurayh NA, Aljebreen MA, Aldukhi SA. Physical activity and majornon-communicable diseases among physicians in Central Saudi Arabia. Saudi Med J. 2016;37(11):1243-50. https://doi.org/10.15537/smj.2016.11.16268 PMid:27761564

24. Al-Nozha MM, Al-Hazzaa HM, Arafah MR, Al-Khadra A, Al-Mazrou YY, Al-Maatouq MA, et al. Prevalence of physical activity and inactivity among Saudis aged 30-70 years. A population-based cross-sectional study. Saudi Med J. 2007;28(4):559-68. https://doi.org/10.1016/j.jsha.2009.06.007 PMid: 17457478

25. Pojskic H, Eslami B. Relationship between obesity, physical activity, and cardiorespiratory fitness levels in children and adolescents in Bosnia and Herzegovina: An analysis of gender differences. Front Physiol. 2018;9:1734. https://doi.org/10.3389/ fphys.2018.01734

PMid:30546322

26. Kristjansdottir G, Vilhjalmsson R. Sociodemographic differences in patterns of sedentary and physically active behavior in older children and adolescents. Acta Paediatr. 2001;90(4):429-35. https://doi.org/10.1111/j.1651-2227.2001.tb00445.x PMid:11332936

27. Trost SG, Owen N, Bauman AE, Sallis JF, Brown W. Correlates of adults' participation in physical activity: Review and update. Med Sci Sports Exerc. 2002;34(12):1996-2001. https://doi. org/10.1097/00005768-200212000-00020 PMid: 12471307

28. Biernat E. Factors increasing the risk of inactivity among administrative, technical, and manual workers in Warszawa public institutions. Int J Occup Med Environ Health. 2015;28(2):283-94. https://doi.org/10.13075/ijomeh.1896.00194 PMid:26182923

29. Sallis JF, Bull F, Guthold R, Heath GW, Inoue S, Kelly P, et al Progress in physical activity over the olympic quadrennium. Lancet. 2016;388(10051):1325-36. https://doi.org/10.1016/ s0140-6736(16)30581-5

PMid:27475270 